\title{
Distribution Characteristics and Hazard
} Analysis of Mountain Torrent Disaster in Guangdong Province, China

\author{
Jun Wang ${ }^{1,2}$, Qinghua Gong ${ }^{1,2}$, Shaoxiong Yuan ${ }^{1,2}$,Haixian Xiong ${ }^{1,2}$, Xiaoling Yin ${ }^{1,2}$ \\ ${ }^{1}$ Guangdong Open Laboratory of Geospatial Information Technology and Application, \\ Guangzhou 510070, China \\ ${ }^{2}$ Guangzhou Institute of Geography, Guangzhou 510070, China

\section{广东省山洪灾害分布特征及危险性分析} \\ 王钧 ${ }^{1,2}$, 宫清华 ${ }^{1,2}$, 袁少雄 ${ }^{1,2}$, 熊海仙 ${ }^{1,2}$, 尹小玲 ${ }^{1,2}$ \\ ${ }^{1}$ 广东省地理空间信息技术与应用重点实验室, 广州 510070, 中国 \\ 2 广州地理研究所, 广州 510070 , 中国
}

\begin{abstract}
Based on the mountain torrent disaster data, a GIS database was established to analyze the distribution characteristics of mountain torrent disasters in Guangdong province, China. Factors such as lithology, slope, elevation, aspect, slope pattern, and distance to river networks were selected to assess hazard degreeby amethod of factor contribution rate. It is found that the mountain torrent disasterwas mainly the medium-sized scale. The Hanjiang River basinhas the most disaster and Chaozhou City has the largestdisasterdistribution density. The Jurassic strata, slope from 10 to $20^{\circ}$, elevation from 300 to $400 \mathrm{~m}$, sunny slope, linear slopepattern, and distance to river networks less than $5 \mathrm{~km}$ have the largest factor contribution rate which are the most prone areas tomountain torrent disasters. The calculated hazard index is between 0.0189 and 0.2592 .The hazard zones can be divided into five zones: safety, low, middle, high and higher zones. The result can provide a basis for mountain torrent disaster mitigation of Guangdong province, China.
\end{abstract}

Keywords:mountaintorrent disaster; distribution characteristics; contribution rate; hazard assessment; Guangdong province

\section{摘要}

基于已发山洪灾害数据, 建立 GIS 数据 库, 对广东省山洪灾害分布特征进行分析; 选择地层岩性、坡度、高程、坡向、坡型、 距水系距离等因子, 采用因子贡献率模型, 对广东省山洪灾害危险性进行评价。结果为: 广东省山洪灾害以中型规模为主, 韩江流域 山洪灾害数量最多, 而潮州市山洪灾害分布 密度最大。侏罗系地层、10 20坡度、 $300 \sim 400 \mathrm{~m}$ 高程、阳坡、线性坡和 $<5 \mathrm{~km}$ 水系 范围, 因子贡献指数最大, 是山洪灾害易发 区间。计算的山洪灾害危险性综合指数在 0.0189 0.2592 之间; 根据该值将危险性划分 为安全区、低危险区、中危险区、较高危险 区和高危险区。研究成果可以为广东省山洪 灾害防灾减灾提供依据。

关键词: 山洪灾害; 分布特征; 贡献指数; 危险性评价; 广东省

\section{1. 引言}

山洪灾害是指因降雨在山丘区引发的洪 水及由洪水诱发的崩塌、滑坡、泥石流等对 国民经济和人民生命财产造成损失的灾害。 
广东省广大丘陵山区由于特殊的地形地貌条 件、地质条件、气象条件和区域生态环境, 导致山洪灾害不断发生, 人民生命财产安全 受到严重威胁。据《广东省山洪灾害防治规 划》, 山洪灾害直接威胁着丘陵山区 77 万城 镇人口、308 万农村人口和固定资产达 312.0 亿元、年产值 331.5 亿元的工矿企业及固定 资产投资达 677.9 亿元的基础设施安全, 威 胁人口占全省人口总数的 $4.5 \%$ 。例如: 广 东省茂名市 2010 年 “9.21” 特大暴雨引发山 洪灾害, 导致 51.7 万人受灾, 1177 间房屋 倒塌, 66 人死亡, 53 人失踪 ${ }^{[2]}$ 。

在山洪灾害的危险分析方面, 目前主要 有两大方法: 统计方法和数值模拟方法 ${ }^{\left[{ }^{2} 5\right]}$ 。 张会等人以辽河中下游为研究区域, 提出了 洪涝灾害风险指数, 用其来评估不同县相关 损失风险及各因子对风险的贡献, 并绘制了 洪涝灾害风险区划图 ${ }^{[6]}$ 。仇劲卫等人根据北 江大堤可能出现的溃堤风险, 模拟了北江大 堤溃决后洪水的演进过程, 得到了淹没水深、 淹没范围、淹没历时及流速等洪水风险信息 [7]。综合分析, 山洪灾害危险性评价已从定 性或半定量评价发展到定量化、模型化操作 的阶段。但由于涉及因子众多、因子选择的 人为性和不确定性, 迄今为止仍是当今世界 正在努力探索, 甚至存严重分歧的问题 ${ }^{[8]}$ 。

为此, 本文采用本底因子贡献率模型进 行广东省山洪灾害危险性分析。以广东省已 发山洪灾害为研究对象, 首先对山洪灾害的 分布特征进行分析; 其次, 构建山洪灾害危 险性评价指标体系, 利用本底因子贡献率模 型确定各评价因子的自权重和互权重; 建立 山洪灾害危险性综合评价模型, 计算得到各 网格山洪灾害危险性综合指数值, 最后进行 山洪灾害危险性分区。

\section{2. 山洪灾害孕灾环境分析}

\section{1 地质条件}

广东省内地层发育齐全, 上古生界碳酸 盐岩和滨海地区第四系软土层广泛分布, 构 成各类地貌的基岩岩石以花岗岩最为普遍, 砂岩和变质岩也较多, 粤西北还有较大片的 石灰岩分布。从地质岩性上看, 山洪灾害主 要发生在松散层厚或软弱及软硬相间的岩层,
特别是母岩为花岗岩风化强烈、裂隙发育地 段。

\section{2 地貌条件}

广东省地貌类型复杂多样, 有山地、丘 陵、台地和平原, 其面积分别占全省土地总 面积的 $33.7 \%$ 、24.9\%、14.2\%和 $21.7 \%$ 。地 势北高南低, 地形可以分为粤北山地区、粤 西山地与沿海台地区、粤东北山地和粤东南 沿海丘陵区、珠江三角洲区。从地貌上看, 山洪灾害大多发生于地形切割强烈、边坡陡 峻的沟谷或陡坡的丘陵低山地带。

\section{3 气象水文条件}

广东省地处亚热带, 雨量充沛, 是全国 光、热和水资源最丰富的地区之一。年平均 气温超过 $20^{\circ} \mathrm{C}$, 年平均降雨量 $1400 \sim 2600$ $\mathrm{mm}$, 降雨量年内分配多呈双峰型, 主峰在 5 月, 次峰在 8 月; 年内最少雨量时期出现在 11 月 次年 1 月。每年 6 月 10 月为广东省受 台风和热带低气压影响的主要时期, 台风往 往伴随着暴雨、特大暴雨, 在山区常常诱发 洪水、崩塌、滑坡、泥石流等山洪灾害。

\section{4 典型山洪灾害实例}

广东省人口众多, 自然地理、地质构造 和气候演变特征复杂。近年来, 随着人类工 程活动对地质环境的改造作用日趋强烈, 导 致山洪灾害活动频繁, 对广东省经济社会的 可持续发展、人居安全等带来了很大的危害。 通过资料搜集, 得到了广东省 2014 年 2016 年已发山洪灾害点 1677 处, 对其进行数字化、 建立各类属性 (类型、地点、坐标、规模、 稳定情况、防治措施、年份等) 数据库, 分 析山洪灾害分布规律, 为山洪灾害危险性定 量分析提供基础数据。近年来广东省主要山 洪灾害实例如表 1 所示。

\section{3. 山洪灾害分布特征}

\section{1 规模特征}

按照山洪灾害发生规模, 将已发的山洪 灾害分为小型、中型、大型、特大型 4 个大 类, 分布图如图 1 所示。 
表 1 近年来广东省主要山洪灾害一览表

\begin{tabular}{|c|c|c|c|}
\hline 位置 & 时间 & 类型 & 危害情况 \\
\hline 恩平市茶水坑水库 & 1998. 6.25 & $\begin{array}{l}\text { 泥石 } \\
\text { 流 }\end{array}$ & 死亡 40 人, 全部经济损失达 5 亿多元 \\
\hline $\begin{array}{c}\text { 翁源县京珠高速公路 } \\
\text { 靠椅山隧道 }\end{array}$ & 1999.9. 6 & $\begin{array}{l}\text { 泥石 } \\
\text { 流 }\end{array}$ & 9 人死亡, 5 人受伤 \\
\hline 兴宁市径心镇 & 2000.4 .30 & $\begin{array}{l}\text { 群发 } \\
\text { 崩塌 }\end{array}$ & 死亡5人, 倒塌房屋 187 间, 经济损失 100 万元 \\
\hline $\begin{array}{c}\text { 佛山市南海区松岗镇 } \\
\text { 南国桃园 }\end{array}$ & 2001.4.24 & 崩塌 & 死亡 8 人, 伤 3 人 \\
\hline $\begin{array}{c}\text { 龙川县赤光、车田及 } \\
\text { 北岭镇 }\end{array}$ & 2003.5. 16 & $\begin{array}{l}\text { 群发 } \\
\text { 崩塌 }\end{array}$ & 死亡 6 人, 倒塌房屋 21 间, 经济损失 50 万元 \\
\hline 兴宁市黄陂镇 & 2003.5 .17 & $\begin{array}{l}\text { 群发 } \\
\text { 崩塌 }\end{array}$ & 死亡 3 人, 倒塌房屋 45 间, 经济损失 120 万元 \\
\hline 从化市105国道 & 2004.4. 11 & 崩塌 & $\begin{array}{c}\text { 毁坏公路边坡及路基18处, 直接经济损失560万 } \\
\text { 元 }\end{array}$ \\
\hline $\begin{array}{c}\text { 饶平新塘镇外宫山角 } \\
\text { 村 }\end{array}$ & 2006.7 .16 & 滑坡 & 死亡 9 人, 伤 8 人 \\
\hline 大埔县西河镇水祝村 & 2006.7 .13 & 滑坡 & 死亡 8 人，摧毁房屋 60 余间 \\
\hline 佛山市南海区西樵山 & 2006.8 .3 & $\begin{array}{c}\text { 泥石 } \\
\text { 流 }\end{array}$ & $\begin{array}{c}\text { 死亡 } 8 \text { 人, 摧毁房间 } 51 \text { 间, 直接经济损失超过 } \\
1.85 \text { 亿元 }\end{array}$ \\
\hline $\begin{array}{l}\text { 深圳市龙岗区布吉街 } \\
\text { 道办木棉湾 }\end{array}$ & 2008. 6.29 & 滑坡 & 死亡 5 人, 伤 18 人 \\
\hline $\begin{array}{c}\text { 深圳市布吉街道办水 } \\
\text { 径石场 }\end{array}$ & 2008.6.29 & $\begin{array}{l}\text { 泥石 } \\
\text { 流 }\end{array}$ & 死亡 3 人, 毁坏矿山采石设备 \\
\hline $\begin{array}{c}\text { 韶关翁源县江尾镇红 } \\
\text { 岭片梅斜村 }\end{array}$ & 2010.5. 2 & $\begin{array}{l}\text { 泥石 } \\
\text { 流 }\end{array}$ & 死亡 1 人、失踪 2 人, 经济损失达 2474 万元 \\
\hline 茂名马贵、信宜等地 & 2010.9.21 & $\begin{array}{c}\text { 崩滑 } \\
\text { 流 }\end{array}$ & 塌房屋 1177 间, 死亡人数 66 人, 53 人失踪 \\
\hline $\begin{array}{c}\text { 韶关市曲江区沙溪镇 } \\
\text { 中心村委 }\end{array}$ & 2013.5.16 & 滑坡 & 3 人死亡, 经济损失 300 万元 \\
\hline $\begin{array}{l}\text { 韶关市乳源县乳城镇 } \\
\text { 大东棉地坑村 }\end{array}$ & 2013. 5. 17 & $\begin{array}{l}\text { 泥石 } \\
\text { 流 }\end{array}$ & 死亡 1 人 \\
\hline $\begin{array}{l}\text { 梅州市五华县安流镇 } \\
\text { 丰联村丰良小组 }\end{array}$ & 2013. 5. 20 & 崩塌 & 死亡 1 人, 经济损失 50 万元 \\
\hline $\begin{array}{l}\text { 肇庆市封开县渔涝镇 } \\
\text { 石便村上榃留山 }\end{array}$ & 2013.6. 11 & 崩塌 & 死亡 3 人, 经济损失 20 万元 \\
\hline $\begin{array}{l}\text { 韶关市乳源县必背镇 } \\
\text { 桂坑村委会泥坑村 }\end{array}$ & 2013.8. 17 & 滑坡 & 1 人死亡。经济损失 100 万元 \\
\hline $\begin{array}{c}\text { 清远市连南县大坪镇 } \\
\text { 大坪村委 }\end{array}$ & 2013.8.18 & 崩塌 & 死亡 3 人, 经济损失 20 万元 \\
\hline 广东肇庆高要市 & 2014.3.31 & 滑坡 & 死亡 6 人, 受伤 1 人 \\
\hline $\begin{array}{c}\text { 韶关市曲江区沙溪镇 } \\
\text { 东华村委 }\end{array}$ & 2015. 5. 11 & 滑坡 & 死亡 1 人 \\
\hline $\begin{array}{c}\text { 广东佛冈 } 6 \text { 个镇 } 32 \text { 个 } \\
\text { 村 }\end{array}$ & 2015.5.17 & 山洪 & $\begin{array}{c}\text { 倒塌房屋 } 6 \text { 间, 受灾人口 } 7200 \text { 人, 受浸农田 } \\
7850 \text { 亩, 道路塌方 } 50 \text { 处, 经济损失 } 1345 \text { 万元 }\end{array}$ \\
\hline $\begin{array}{c}\text { 梅州市五华县潭下镇 } \\
\text { 竹梅村七组 }\end{array}$ & 2015. 5. 25 & 崩塌 & 死亡 1 人, 经济损失 20 万元 \\
\hline $\begin{array}{c}\text { 茂名信宜市新宝镇枫 } \\
\text { 木村扶垌 }\end{array}$ & 2015. 10.3 & 滑坡 & 死亡 2 人 \\
\hline $\begin{array}{l}\text { 肇庆市广宁县江屯镇 } \\
\text { 新坑村委深坑养殖场 }\end{array}$ & 2015. 10.5 & 崩塌 & 死亡 2 人, 伤 1 人 \\
\hline 深圳光明长圳洪浪村 & 2015.12 .20 & 滑坡 & 造成多栋楼坍塌、58 人遇难 \\
\hline 广东龙川县 & 2016.4.19 & 山洪 & 东江水位比平时高出 1 米多, 洪水泛滥 \\
\hline 茂名信宜 & 2016. 5.20 & 山洪 & 54 万多人受灾、8 人死亡 \\
\hline
\end{tabular}




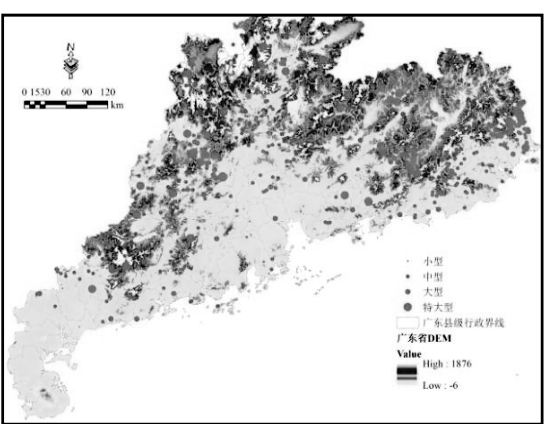

图 1 广东省不同规模的山洪灾害分布图

分类统计每个类型的数量, 统计饼图如 图 2 所, 可以看出: 中型规模的山洪灾害最 多, 占了总数量的 $54.68 \%$, 在全省范围内广 泛分布; 特大型规模灾害分布最少, 占总数 量的 $4.53 \%$, 主要分布在韶关市乳源县, 河 源市连平县、紫金县、和平县, 肇庆市德庆 县、广宁县、四会市, 潮州市饶平县, 揭阳 普宁市, 云浮罗定市, 茂名高州市等地。

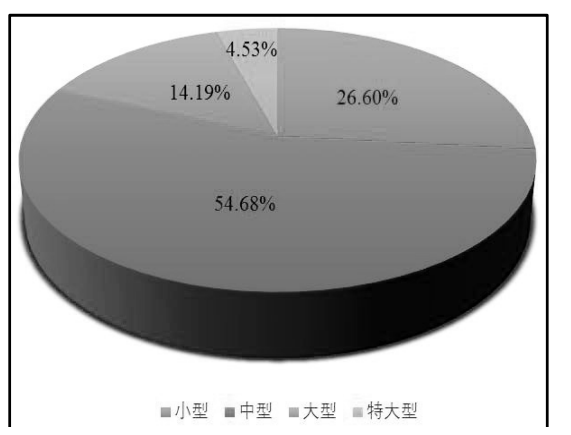

图 2 山洪灾害规模统计饼状图

\section{2 流域特征}

将广东省按韩江流域、北江流域、西江 流域、东江流域、粤西沿海、珠江三角洲分 为 6 大流域, 如图 3 所示, 分类统计几大流 域的灾害数量、比例、分布密度, 发现韩江 流域灾害数量最多, 占了总数量的 $42.16 \%$, 其次为北江流域, 占比为 $26.48 \%$; 珠江流域 最少, 数量仅为总数量的 $5.13 \%$ 。就灾害分 布密度而言, 韩江流域灾害密度最大, 达到 了 0.021 个 $/ \mathrm{km}^{2}$, 其次依次为北江流域、西 江流域、东江流域、粤西沿海和珠江三角洲。

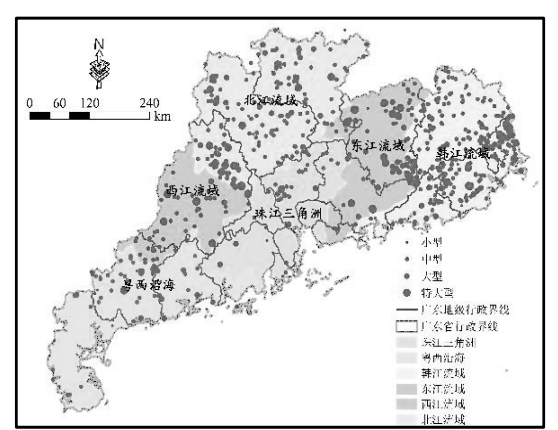

图 3 广东省不同流域山洪灾害分布图

\section{3 行政区域特征}

按广东省市级行政界限划分, 如表 2 所 示。山洪灾害分布密度最大的为潮州市, 灾 害分布密度为 0.0293 个 $/ \mathrm{km}^{2}$, 其次为揭阳市、 汕头市、梅州市和河源市, 山洪灾害最小的 为珠海市和中山市, 分布密度均为 0.0006 个 $/ \mathrm{km}^{2}$ 。

表 2 按地级市行政区域统计的山洪灾害表

\begin{tabular}{ccc}
\hline 市名 & 面积 $/ \mathrm{km}^{2}$ & 灾害分布密度 $/$ 个 $/ \mathrm{km}^{2}$ \\
\hline 潮州市 & 3613.9 & 0.0293 \\
揭阳市 & 5240 & 0.0162 \\
汕头市 & 2064 & 0.0131 \\
梅州市 & 15925 & 0.0104 \\
河源市 & 15821 & 0.0092 \\
汕尾市 & 5271 & 0.0085 \\
肇庆市 & 15000 & 0.0082 \\
韶关市 & 18600 & 0.0065 \\
茂名市 & 11445 & 0.0064 \\
清远市 & 19000 & 0.0063 \\
广州市 & 7434.4 & 0.0051 \\
云浮市 & 7779 & 0.0042 \\
阳江市 & 7813.4 & 0.0029 \\
江门市 & 2019 & 0.0025 \\
惠州市 & 11200 & 0.0024 \\
东莞市 & 2465 & 0.0012 \\
湛江市 & 12490 & 0.0010 \\
佛山市 & 3868 & 0.0008 \\
珠海市 & 1701 & 0.0006 \\
中山市 & 1800.1 & 0.0006 \\
\hline 中.
\end{tabular}

\section{4. 山洪灾害危险性评估模型}

\section{1 评价模型}

选用贡献率模型对山洪灾害危险行进行 评价。众所周知, 每一个评价因子指标对灾 害发育作出的贡献不同。因此, 在可靠的灾 
害数据基础上, 选用量密度指标进行因子贡 献程度评价。贡献率指数是评价因子对山洪 灾害危险性贡献程度的重要指标之一, 如下 式:

$$
\bar{U}_{i}^{\prime}(\%)=\bar{U} / \bar{V} \times 100 \% \text { (1) }
$$

式中, $\bar{U}_{i}^{\prime}$ 为因子贡献指数, $\bar{U}$ 为各评价因子 子集内的山洪灾害数, $\bar{V}$ 为各评价因子的总 山洪灾害数。

贡献率通过贡献率指数进行计算:

$$
U_{o i}(\%)=\bar{U}_{i}^{\prime} / \sum \bar{U}_{i}^{\prime} \times 100 \%
$$

式中, $U_{o i}$ 为因子 $o$ 中第 $i$ 个评价因子的贡献 率, $\sum \bar{U}_{i}^{\prime}$ 为评价因子的贡献率指数之和。

各评价因子内部的自权重计算公式为:

$$
w_{i}=U_{o i} / \sum U_{o i}
$$

式中, $w_{i}$ 为地质灾害评价因子 $i$ 的自权重, $U_{o i}$ 为因子 $o$ 中第 $i$ 个评价因子的贡献率。

各评价因子的互权重通过下式计算:

$$
w_{i}^{\prime}=U_{j}^{\prime \prime} / \sum U_{j}^{\prime \prime}
$$

式中, $w_{i}^{i}$ 为地质灾害评价因子 $i$ 的互权重, $U_{j}^{\prime \prime}=\sum U_{o i}$ 为因子的综合贡献率, $j=1 \cdots n$ 。

各因子自权重和互权重相乘并进行叠加, 得到广东省山洪灾害危险性评价模型:

$$
Z=\sum_{i=1}^{n} w_{i} w_{i}^{\prime} U_{o i}^{\prime}(5)
$$

式中, $Z$ 为山洪灾害危险性综合指数, $w_{i}$ 为 山洪灾害评价因子 $i$ 的自权重, $w_{i}^{\prime}$ 为山洪灾 害评价因子 $i$ 的互权重, $U_{o i}^{\prime}$ 为各山洪灾害评 价因子的贡献指数。

\section{2 评价因子及贡献指数计算}

根据广东省山洪灾害发育特征和区域地 质条件, 结合数据的可获取性, 借鉴前人相 关研究成果, 经过专家讨论和综合研判, 选 择广东省的地层岩性、高程、坡度、坡向、 坡型、距水系距离等 6 大因子, 构建广东省 山洪灾害危险性评价指标体系。

（1）地层岩性

采用 1:250 万电子地质图及说明材料, 将广东省地层岩性划分为 23 类参与山洪灾害 的危险性分析, 计算的各地层的贡献率 (图 4)。侏罗系地层的贡献率高, 是山洪灾害的 主要发育地层, 贡献指数为 0.356 。

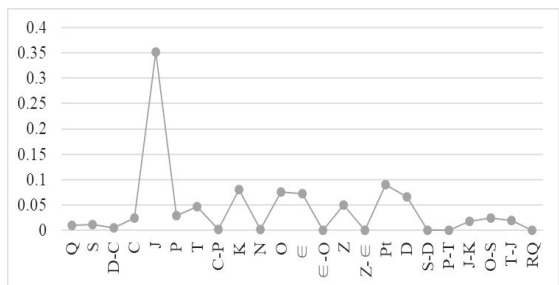

图 4 地层岩性贡献率图

（2）地形坡度

将广东省坡度划分为 $0 \sim 10^{\circ} 、 10 \sim 20^{\circ}$ 、 $20 \sim 30^{\circ} 、 30 \sim 40^{\circ} 、 40 \sim 50^{\circ}$ 和大于 $50^{\circ}$ 共 6 个属性, 贡献率如图 5。10 $\sim^{\circ} 20^{\circ}$ 坡度对山洪灾 害的贡献率高, 贡献指数为 0.655 。

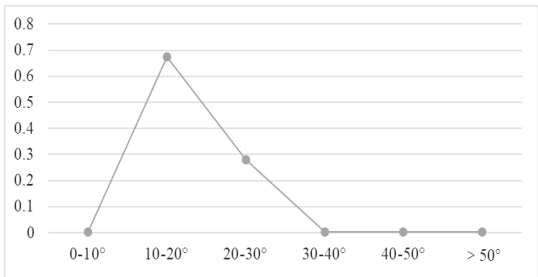

图 5 坡度贡献率图

\section{(3) 高程}

将广东省高程按 $100 \mathrm{~m}$ 区间分为 $0 \sim 100 \mathrm{~m}$ 、 $100 \sim 200 \mathrm{~m} 、 200 \sim 300 \mathrm{~m} 、 300 \sim 400 \mathrm{~m} 、 400 \sim$ $500 \mathrm{~m} 、 500 \sim 600 \mathrm{~m} 、 600 \sim 700 \mathrm{~m} 、 700 \sim 800 \mathrm{~m}$ 大于 $800 \mathrm{~m}$ 共 9 个属性, 贡献率如图 6 。 $300^{\sim} 400 \mathrm{~m}$ 的高程区间对山洪灾害贡献率最高, 贡献指数分别为 0.345 。

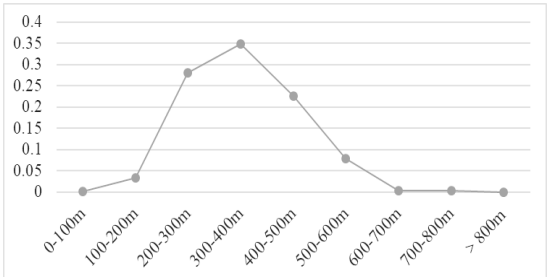

图 6 高程贡献率图

(4) 坡向

为了掌握山洪灾害点分布的坡向规律性, 将其分为阴坡和阳坡，计算其贡献率（图 7)。 阳坡的对山洪灾害的贡献率高, 贡献指数为 0.554 , 阴坡对山洪灾害的贡献率最低, 贡献 指数为 0.446 。 


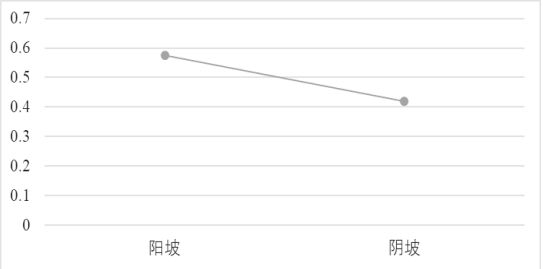

图 7 地形坡向贡献率图

(5) 坡型

将坡形分为 5 种: 凹形坡、上凹下凸形 坡、直线形坡、凸形坡、上凸下凹形坡。根 据数据库中灾害的具体位置, 获得各类坡形 对灾害数量的贡献指数 (图 8)。坡型为直线 型的斜坡对山洪的贡献率高, 贡献指数为 0.614 , 其次为上凹下凸的斜坡。

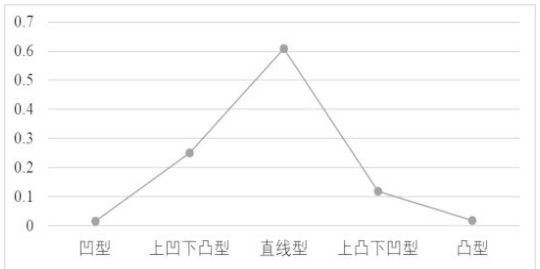

图 8 坡型贡献率图

（6）距离水系距离

将研究区的主要水系按照 $5 \mathrm{~km} 、 10 \mathrm{~km}$ 、 $15 \mathrm{~km}$ 和 $30 \mathrm{~km}$ 进行缓冲, 得到距水系距离图 层, 根据数据库中灾害的位置, 获得各类水 系距离对灾害数量的贡献指数（图 9)。可以 看出, 小于 $5 \mathrm{~km}$ 范围的水系缓冲距离对山洪 灾害的贡献率最高, 贡献指数为 0.327 , 其次 为 $5 \sim 10 \mathrm{~km}$ 范围。

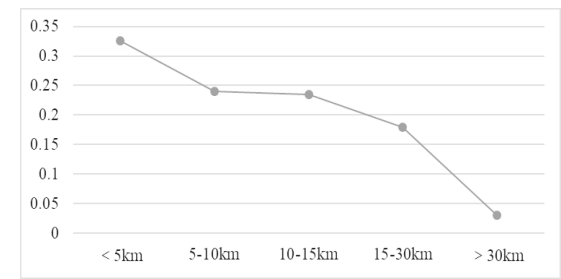

图 9 距水系距离贡献率图

\section{3 危险性评价结果和验证}

根据计算的各评价因子的贡献指数, 根 据式（3）和（4）依次计算各评价因子的自 权重和互权重, 然后按式 (5) 进行山洪灾害
危险性综合指数的计算。得到广东省山洪灾 害危险性综合指数分布在 $0.0189^{\sim} 0.2592$ 之 间，根据该值采用自然临近插值法对广东省 连续空间上的山洪灾害危险度区划进行分区, 得到 5 个划分区间: 安全区, 低危险度区、 中危险度区, 较高危险度区和高危险度区, 如图 10 所示。

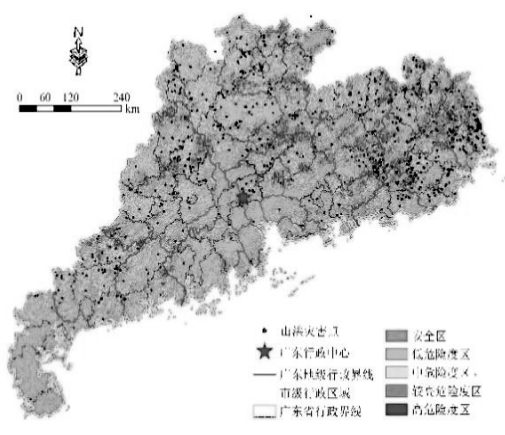

图 10 广东省山洪灾害危险性分析结果图

利用广东省山洪灾害点对划分结果进行 检验。从密度分布 (每平方公里内滑坡泥石 流地质灾害点的个数) 曲线（图 11）可以看 出, 从安全区到高危险度区, 灾害点分布密 度逐渐增高, 评价结果基本合理。

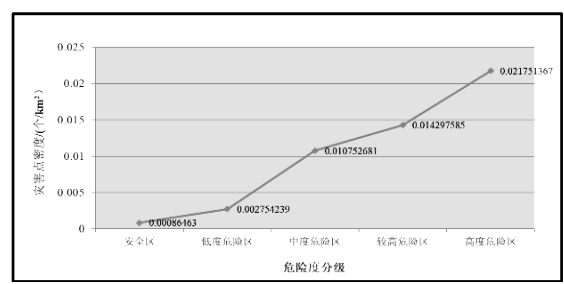

图 11 危险度级别与样本灾害点分布密度图

\section{5. 结论}

广东省山洪灾害规模以中型规模为主, 韩江流域和潮州市灾害分布密度最大。侏罗 系地层、 $10^{\sim} 20^{\circ} 、 300^{\sim} 400 \mathrm{~m}$ 、阳坡、直线型 坡和 $<5 \mathrm{~km}$ 水系范围, 因子贡献指数最高, 为山洪灾害易发区间。危险性综合指数值为 $0.0189^{\sim} 0.2592$; 根据该值将广东省山洪灾害 危险性划分为安全区、低危险区、中危险区、 较高危险区和高危险区。

\section{Acknowledgements}

This study was supported by the GDAS' Special Project of Science and Technology Development (2017GDASCX-0803 、2017GDASCX-0101), 
Natural Science Foundation of Guangdong Province (2018A030310469), Water Resource Science and Technology Innovation Program of Guangdong Province (2016-15),Science and Technology Plan Projects of Guangzhou (201804010126、201803030025), and CRSRI Open Research Program (CKWV2017524/KY).

\section{致谢}

本研究得到了广东省科学院创新人才引进专 项(2017GDASCX-0803、2017GDASCX-0101)、 广东省自然科学基金(2018A030310469)、广 东省水利厅科技创新项目(2016-15)、广州市 科技计划项目(201804010126、201803030025)、 长江科学院开放研究基金资助项目 (CKWV2017524/KY)的联合资助。

\section{参考文献}

[1] http://wenku.baidu.com/view/bdfd7524aae a998fcc $220 \mathrm{e} 22 . \mathrm{html}$ ?pn=50.

[2] 王永喜,夏兵,粤西台风灾区水土保持生态 修复策略和措施一以高州市马贵镇为例. 中国水土保持科学,2012, 10(1): 88-93.

[3] Kashiwagi D, Kashiwagi J. A new risk management model. Journal of Risk Analysis and Crisis Response,2012, 2(4): 233-251.

[4] Sousa V, Almeida N M D, Dias L A, Risk management framework for the construction industry according to the ISO 31000:2009 standard. Journal of Risk Analysis and Crisis Response, 2012, 2(4): 261-274.

[5] Tuladhar G. Disaster management system in Nepal-policy issues and solutions. Journal of Risk Analysis and Crisis Response,2012,2(3): 166-172.

[6] 张会, 张继权, 韩俊山,基于 GIS 技术的洪 涝灾害风险评估与区划研究一以辽河中 下游地区为例. 自然灾害学报,2005, 14(6): 141-146.

[7] 仇劲卫, 陆吉康, 李娜, 等, 北江大堤洪水 风险图信息管理系统中仿真模型的开发 研究. 灾害学, 1999, 14(4): 17-21.

[8] 张丽, 李广杰, 周志广, 等,基于灰色聚类 的区域地质灾害危险性分区评价. 自然灾 害学报, 2009, 18(1): 164-168. 